\title{
Lymphoscintigraphy detecting alterations of upper limb lymphatic flow following early sentinel lymph node biopsy in breast cancer
}

This article was published in the following Dove Press journal:

Breast Cancer - Targets and Therapy

19 April 2017

Number of times this article has been viewed

\author{
Almir Jose Sarri' \\ Eduardo Tinois da Silva ${ }^{2}$ \\ Rene Aloisio da Costa \\ Vieira ${ }^{3}$ \\ Katia Hiromoto Koga ${ }^{2}$ \\ Pedro Henrique Moriguchi \\ Cação ${ }^{4}$ \\ Vitor Coca Sarri ${ }^{5}$ \\ Sonia Marta Moriguchi ${ }^{2}$ \\ 'Department of Physical Therapy, \\ Barretos Cancer Hospital, Barretos, \\ Sao Paulo, ${ }^{2}$ Department of Tropical \\ Diseases and Diagnostic Imaging, \\ Botucatu Medical School, Sao \\ Paulo State University - UNESP, \\ Botucatu, ${ }^{3}$ Department of Mastology \\ and Reconstructive Surgery, \\ Barretos Cancer Hospital, Barretos, \\ ${ }^{4}$ Department of Radiology - \\ Faculdade de Medicina de São José do \\ Rio Preto (FAMERP), ${ }^{5}$ Medical School, \\ University of Franca, Sao Paulo, Brazil
}

Correspondence: Sonia Marta Moriguchi Department of Tropical Diseases and Diagnostic Imaging, Botucatu Medical School, Sao Paulo State University UNESP, Campus Botucatu - Av. Prof. Montenegro, s/n - Distrito de Rubião Junior, CEP I86 I8-970, Botucatu, Sao Paulo, Brazil

Tel +55 I4 38II 6133

$\mathrm{Fax}+551438159898$

Email soniamoriguchi@gmail.com
Purpose: To evaluate early variations in lymphatic circulation of the arm pre- and post-sentinel lymph node biopsy (SLNB) and conservative breast surgery by lymphoscintigraphy (LS).

Patients and methods: Between 2005 and 2012, 15 patients underwent LS before and after the SLNB (total=30 studies). The pre-SLNB study was considered the control. Early images within twenty minutes (dynamic and static images) and delayed images within ninety minutes of arms and armpits were acquired using a gamma camera. The LS images before and after the SLNB of each patient were paired and compared to each other, evaluating the site of lymphatic flow (in the early phase) and identifying the number of lymph nodes (in the late phase). These dynamic images were subjected to additional quantitative analysis to assess the lymphatic flow rate using the slope assessed by the angular coefficient of the radioactivity $\times$ time curves in areas of interest recorded in the axillary region. The variations of lymphatic flow and the number of lymph nodes in the post-SLNB LS compared to the pre-SLNB LS of each patient were classified as decreased, sustained or increased. The clinical variables analyzed included the period between performing the SLNB and the subsequent LS imaging, age, body mass index, number of removed lymph nodes, type of surgery and whether immediate oncoplastic surgery was performed.

Results: The mean age was $54.53 \pm 9.03$ years ( $36-73$ years), the mean BMI was $27.16 \pm 4.16 \mathrm{~kg} /$ $\mathrm{m}^{2}$ (19.3-34.42), and the mean number of lymph nodes removed from each patient was $1.6 \pm 0.74$ (1-3). There was significant difference in the time between surgery and the realization of LS ( $p=0.002$; Mann-Whitney U test), but in an inverse relationship, the higher was the range, the smaller was the lymphatic flow, indicating a gradual reduction of lymphatic flow after surgery (Spearman's $p=0.498$, with $p=0.013$ ).

Conclusion: Upper limb lymphatic flow gradually decreased after the SLNB and conservative breast surgery in this study, but these results are exploratory because of the small sample size. Further studies are needed to confirm and to investigate more in depth these findings.

Keywords: lymph node sentinel biopsy, lymphoscintigraphy, nuclear medicine, lymphedema, breast cancer

\section{Introduction}

Breast cancer is one of the most common causes of death in women, with increasing incidence in developed and developing countries. ${ }^{1}$ It requires more aggressive and costly treatments in advanced stages, ${ }^{2,3}$ which can cause more immediate or delayed posttreatment complications, including bleeding, infection, seroma, axillary web syndrome, chronic pain, paresthesia due to intercostal brachial nerve injury, decreased range of motion and muscle weakness in the shoulder and, especially, lymphedema., ${ }^{4,5}$ The latter is the largest and most important morbidity, ${ }^{6,7}$ with increased incidence when associated with complementary radiation therapy. ${ }^{8-10}$ 
Lymphedema is difficult to diagnose, especially in the early stages. ${ }^{911}$ It is incurable when established. Studies show that surgery and drug therapies are unsuccessful, ${ }^{12,13}$ although lymphedema may be avoided, treated and controlled by daily preventive measures. ${ }^{14,15}$ Improper diagnosis always causes delayed therapy and at a more advanced stage of morbidity. Early treatment leads to fast improvement and prevents lymphedema progression. ${ }^{9,16}$

Lymphedema prevention has been attempted using more conservative intraoperative methods of approach to the axillary chain, including the sentinel lymph node biopsy (SLNB). The authors have introduced innovative methods in recent decades, accounting for a new standard of care for early-stage patients. ${ }^{17,18}$ These improvements enable selective, safer and less mutilating resections with satisfactory results and a substantial reduction of surgical morbidity, ${ }^{19,20}$ albeit restricted to patients with clinically negative axilla. ${ }^{21,22}$

The sentinel lymph node (SLN) is the first node receiving lymphatic drainage from the primary tumor. ${ }^{23,24}$ Increasing focus on morbidity triggered by axillary lymph node dissection (ALND) and toward increasing the capacity of detection of small tumor cells in the SLN have increased the indication of SLNB ${ }^{25}$ because this method is safe and less invasive, with reduced treatment costs. ${ }^{26,27}$

The primary goals of SLNB were to generate information on the stage of the axillary chain and to avoid unnecessary axillary dissection, decreasing upper limb morbidities. These morbidities are lesser in SLNB than in ALND, ${ }^{28-30}$ improving the patient's quality of life. ${ }^{31}$ Although the application of SLNB has increased, its use reduces but does not eliminate the risk of developing lymphedema, ${ }^{32,33}$ with the incidence ranging from $0 \%$ to $15.8 \% .{ }^{34-36}$ The transection of arm lymph vessels during $\mathrm{SLNB}^{37,38}$ and obesity ${ }^{38,39}$ may trigger lymphedema. Britton et $\mathrm{a}^{40}$ also found a small number of patients with a coincidental SLN draining the breast and upper limb, the removal of which causes the disruption of lymphatic drainage of the upper limb, consequently increasing the risk of developing lymphedema. Several authors are using axillary reverse mapping to avoid injuring coincidental lymph vessels. ${ }^{41-44}$

Lymphoscintigraphy (LS) is an available, inexpensive, easily performed, low-morbidity complementary imaging method. It is based on the principle that radiocolloids and radiolabeled macromolecules of appropriate size and properties injected in the interstitial tissue reach afferent lymph vessels and are transported to lymph nodes, mapping the lymphatic system. Colloids labeled with ${ }^{99 \mathrm{~m}} \mathrm{Tc}$ are the most used radiotracers and can effectively assess the lymph systems of the upper and lower limbs, although most publications focus their lymphatic studies on the lower limbs..$^{33,45}$ The introduction of nuclear medicine concept in mastology for SLN identification is widespread. The use of vital dyes or radiopharmaceuticals alone or in combination is very effective for the accurate identification of lymph nodes. ${ }^{46-48}$

LS of the upper limbs after mastectomy was used to evaluate treatment efficacy after physical therapy of the arm with lymphedema already established. Recently, we conducted a study to assess lymph flow in the upper limbs with and without physical therapy stimulation in recently mastectomized patients submitted to ALND and without lymphedema. LS effectively illustrated the improvements in poststimulation lymph flow, directing early physical therapy behaviors in the group of patients at potential risk of developing late lymphedema. ${ }^{49}$ We have found no evidence for evaluation of the lymphatic circulation following immediate conservative breast surgery with SLNB in the literature.

The objective of this study was to evaluate early variations in lymphatic circulation of the arm pre- and post-SLNB and conservative breast surgery by LS.

\section{Patients and methods}

This longitudinal observational study included 26 patients aged $>18$ years with unilateral breast cancer who were submitted to SLNB between 2005 and 2012. A total of 11 patients were excluded, including four submitted to ALND during surgery, given the identification of lymph node metastases in the biopsies, two with no good quality of LS images and five who withdrew their consent during the study. The final sample consisted of 15 patients who underwent LS before and after the SLNB for a total of 30 studies; the pre-SLNB study was considered the control. None of the patients submitted to previous chemotherapy or radiation therapy with knowledge of lymphatic pathology prior to SLNB and with the presence of inflammatory or infectious processes associated with the upper limbs were included. The patients were informed about the study and freely signed the informed consent form; the study received approval from the Research Ethics Committee of Barretos Cancer Hospital, Brazil.

LS images were acquired and processed according to the protocol proposed by Sarri et a $1^{49}$ using a two-headed, lowenergy collimator and high-resolution nuclear gamma camera (GE Medical Systems Israel Ltd, Millennium VG Hawkeye, Tirat Hacarmel, Israel), with acquisition of early images of the arms and armpits (dynamic phase [DYNAMIC] - one frame/minute for 20 minutes); the static immediate phase (STATIC, images of the arms and axillary regions for 10 
minutes each) started immediately after the dynamic phase, and the delayed-phase whole-body scan (WBS) images were acquired 90 minutes after the injection of $0.5 \mathrm{~mL}$ of $37 \mathrm{MBq}$ (99m)Tc-phytate (Nuclear and Energetic Research Institute - IPEN, FITA-TEC fitato de sódio [99m Tc], São Paulo, Brazil), which was administered subcutaneously (fan technique) into the second interdigital space. ${ }^{49}$ The LS images before and after the SLNB of each patient were paired and compared to each other, evaluating the site of lymphatic flow (in the early phase) and identifying the number of lymph nodes (in the late phase). The sequential ordinal classification from the injection site in the hand to the farthest site reached, which ranged from 0 to 14 , as proposed by Sarri et $\mathrm{al}^{49}$ and as shown in Figure 1, was used to locate the site of the afferent lymphatic inflow junction in the upper limb. The dynamic images were subjected to additional quantitative analysis to assess the lymphatic flow rate using the slope assessed by the angular coefficient of the activity $\times$ time curves in areas of interest recorded in the axillary region. ${ }^{49}$ The variations of lymphatic flow and the number of lymph nodes in the postSLNB LS compared to the pre-SLNB LS of each patient were classified as decreased, sustained or increased.

\section{Results}

The mean age of the analyzed sample $(n=15)$ was $54.53 \pm 9.03$ years (36-73 years), the mean body mass index (BMI) was
$27.16 \pm 4.16 \mathrm{~kg} / \mathrm{m}^{2}$ (minimum - maximum: 19.3-34.42), and the mean number of lymph nodes removed from each patient was 1.6 \pm 0.74 (minimum - maximum: $1-3$ ).

The tumors were predominantly in the left breast $(n=11$; $73.4 \%)$ compared to the right breast $(n=4 ; 26.0 \%)$. Quadrantectomy was the procedure of choice $(n=13 ; 86.0 \%)$, followed by simple mastectomy $(n=2 ; 14.0 \%)$. An immediate oncoplastic surgery was performed in three patients.

Comparisons between the site of the afferent lymphatic inflow junction and the total number of lymph nodes identified and the subsequent classifications into decreased, sustained or increased for each group of images were made after pairing the dynamic, static and WBS images from the pre- and post-SLNB studies of each patient. Only two subgroups were formed for statistical analysis purposes: patients with decreased (decreased group, DG) versus patients with sustained/increased (sustained/increased group, SIG) lymphatic flow and number of lymph nodes post-SLNB. The clinical variables analyzed included the period between performing the SLNB and the subsequent LS imaging, age, BMI, number of removed lymph nodes, type of surgery and whether immediate oncoplastic surgery was performed.

Dynamic image analysis identified eight patients with decreased $(\mathrm{DG}=8)$ and seven with sustained/increased lymphatic flow rates $(\mathrm{SIG}=7)$. No statistically significant

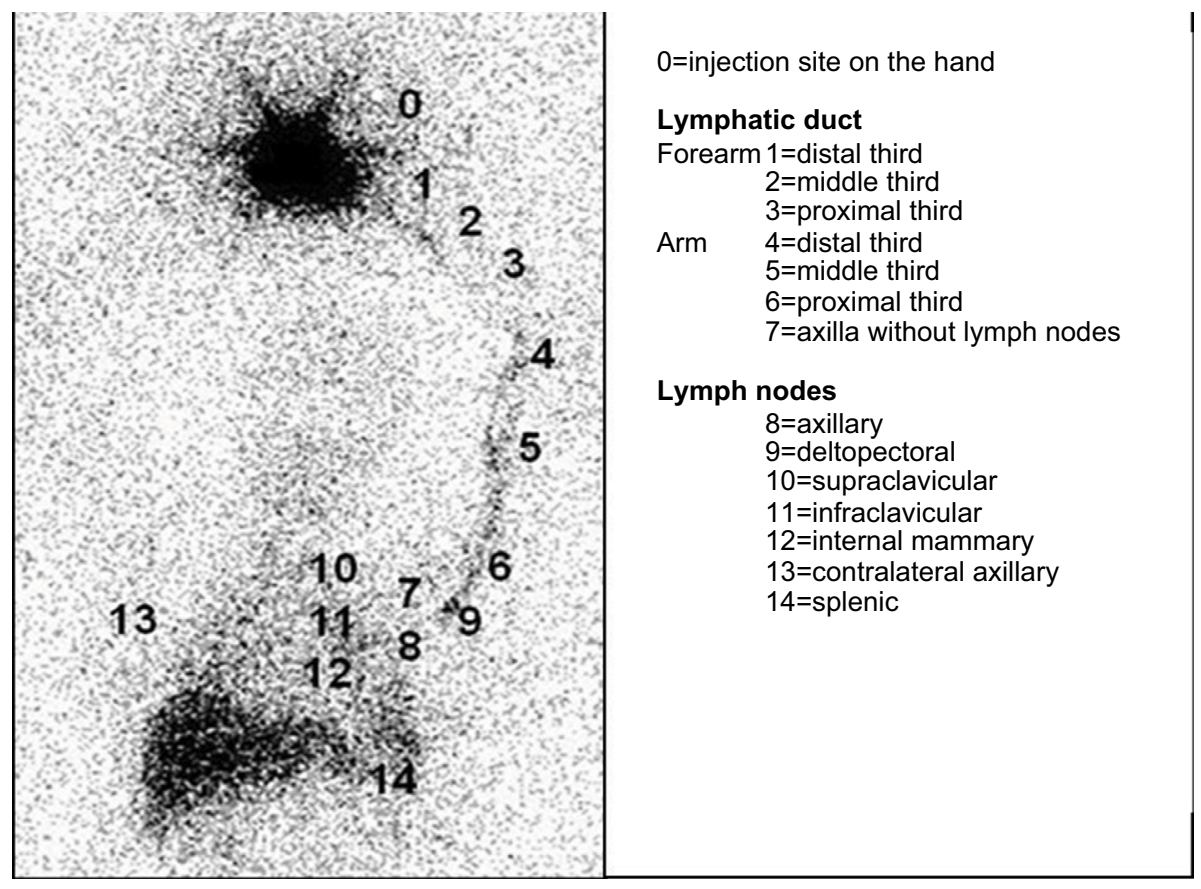

Figure I Lymphoscintigraphy including the area from the hand to the abdominal region.

Notes: Sequential ordinal classification of the site reached by lymphatic flow from the injection site (minimum classification) to the spleen (maximum classification). Reprinted with permission from Spandidos Publications UK Ltd. Sarri AJ, Moriguchi SM, Dias R, et al. Physiotherapeutic stimulation: early prevention of lymphedema following axillary lymph node dissection for breast cancer treatment. Exp Ther Med. 2010;I(I):147-152. Copyright (C) 2010, Spandidos Publications. ${ }^{49}$ 
differences were observed between the variables, as shown in Table 1. Both patients submitted to simple mastectomy showed a decreased lymphatic flow rate, seven of the 13 patients submitted to quadrantectomy showed an increased lymphatic flow rate and six showed a decreased rate without significant lymphatic variation associated with the surgical approach ( $p=0.467$, Fisher's exact test). The lymphatic flow rate increased after the SLNB in the three patients submitted to immediate oncoplastic surgery, which proved to be a key factor ( $p=0.07$, Fisher's exact test).

Analysis of the static image (STATIC) revealed a significant difference between DG $(n=6)$ and SIG $(n=9)$ with regard to the variable site of the afferent lymphatic inflow junction and the time period between the SLNB and the post-SLNB LS scan ( $p=0.002$, Mann-Whitney U test), albeit in an inverse relationship: the longer the period is, the smaller the site of the afferent lymphatic inflow junction will be, indicating a gradual decrease of lymphatic flow post-SLNB ( $\rho=-0.498$, with $p=0.013$; Spearman's rank correlation coefficient - Spearman's $\rho$ ). No statistically significant differences were noted in that image regarding the other variables analyzed, as shown in Table 2. The representative figure depicts the data in a box plot (Figure 2).

When analyzing the clinical variables, no statistically significant differences were observed between the subgroups formed using the criterion decreased (DG) versus sustained/increased
(SIG) variation of the total number of lymph nodes identified in each study phase. One to three axillary lymph nodes were identified, although the uptake intensity changed in WBS images.

\section{Discussion}

An SLNB in patients submitted to early-stage breast cancer treatment is a strategy to minimize the risk of morbidities associated with therapy, primarily upper limb lymphedema. ${ }^{3,4,50}$ Currently, the decrease in practice of ALND after positive SLN for micrometastases or an isolated tumor suggests that ALND is more prognostic than therapeutic. ${ }^{51-53}$ Although SLNB reduces the risk of developing lymphedema, other factors, including disruption of arm lymphatic vessels ${ }^{37,38}$ and obesity, ${ }^{38,39}$ may lead to the onset of this condition, especially when associated with adjuvant radiation therapy. 8,9 McLaughlin et $\mathrm{al}^{54}$ verified that $50 \%$ of patients submitted to SLNB were concerned with the development of lymphedema, in contrast to $75 \%$ of those submitted to ALND in their study. This concern is understandable in this group of patients, although it is unfounded in the SLNB group, given the low risk of developing lymphedema. Our study showed no early change in lymphatic flow related to BMI.

Nuclear medicine technology has a key role in the evaluation of the lymphatic system. ${ }^{55}$ Considering the system's complexity, X-ray images remain a challenge because the

Table I Lymphatic flow velocity (angular coefficient). Paired variables analysis of lymphatic flow rate in early dynamic images in the decreased (DG) versus sustained/increased (SIG) subgroups

\begin{tabular}{llllllll}
\hline Variable & Subgroup & $\mathbf{n}$ & Mean (SD) & Min-max & Median & $\mathbf{9 5 \%}$ Cl & p-value* \\
\hline Period (days) & DG & 8 & $30.88 \pm 6.47$ & $22.00-40.00$ & 32.50 & $26.30 ; 35.45$ & 0.867 \\
& SIG & 7 & $33.14 \pm 14.10$ & $20.00-61.00$ & 34.00 & $22.48 ; 43.80$ & 0.613 \\
Age (years) & DG & 8 & $53.63 \pm 10.82$ & $36.00-73.00$ & 55.50 & $45.97 ; 61.28$ & $50.16 ; 60.98$ \\
BMI (kg/m) & SIG & 7 & $55.57 \pm 7.16$ & $46.00-64.00$ & 55.00 & $17.98 ; 33.28$ & 0.094 \\
& DG & 8 & $25.63 \pm 10.82$ & $19.33-29.30$ & 25.81 & $25.60 ; 32.20$ & $0.97 ; 2.03$ \\
RLN (number) & SIG & 7 & $28.90 \pm 4.37$ & $21.64-34.42$ & 29.30 & 0.613 \\
& DG & 8 & $1.50 \pm 0.76$ & $1.00-3.00$ & 1.00 & $1.14 ; 2.29$ \\
\hline
\end{tabular}

Notes: Period, period between SLNB and LS; *Mann-Whitney $U$ test.

Abbreviations: SLNB, sentinel lymph node biopsy; LS, lymphoscintigraphy; BMI, body mass index; RLN, removed lymph nodes; SD, standard deviation; Cl, confidence interval.

Table 2 Site of the afferent lymphatic inflow junction in Static Images (STATIC). Paired variables analysis in the decreased (DG) versus sustained/increased (SIG) subgroups

\begin{tabular}{|c|c|c|c|c|c|c|c|}
\hline Variable & Subgroup & $\mathbf{n}$ & Mean (SD) & Min-max & Median & $95 \% \mathrm{Cl}$ & $p$-value* \\
\hline \multirow[t]{2}{*}{ Period (days) } & DIG & 6 & $40.33(10.33)$ & $34.00-61.00$ & 36.00 & $31.90 ; 48.77$ & 0.002 \\
\hline & SIG & 9 & $26.33(5.77)$ & $20.00-35.00$ & 23.00 & $21.63 ; 30.18$ & \\
\hline \multirow[t]{2}{*}{ Age (years) } & DIG & 6 & $52.33(9.77)$ & $36.00-62.00$ & 52.50 & $44.36 ; 60.31$ & 0.607 \\
\hline & SIG & 9 & $56.00(8.77)$ & $45.00-73.00$ & 56.00 & $50.15 ; 61.85$ & \\
\hline \multirow[t]{2}{*}{ BMI $\left(\mathrm{kg} / \mathrm{m}^{2}\right)$} & DIG & 6 & $28.40(5.75)$ & 19.33-34.42 & 29.32 & $23.71 ; 33.10$ & 0.224 \\
\hline & SIG & 9 & $26.32(2.76)$ & $21.64-29.30$ & 26.77 & $24.49 ; 28.16$ & \\
\hline \multirow[t]{2}{*}{ RLN } & DIG & 6 & $2.00(0.89)$ & $1.00-3.00$ & 2.00 & $1.27 ; 2.73$ & 0.181 \\
\hline & SIG & 9 & $1.33(0.50)$ & $1.00-2.00$ & 1.00 & $1.00 ; 1.67$ & \\
\hline
\end{tabular}

Notes: Period, period between SLNB and LS; *Mann-Whitney $U$ test.

Abbreviations: SLNB, sentinel lymph node biopsy; LS, lymphoscintigraphy; BMI, body mass index; RLN, removed lymph nodes; SD, standard deviation; Cl, confidence interval. 


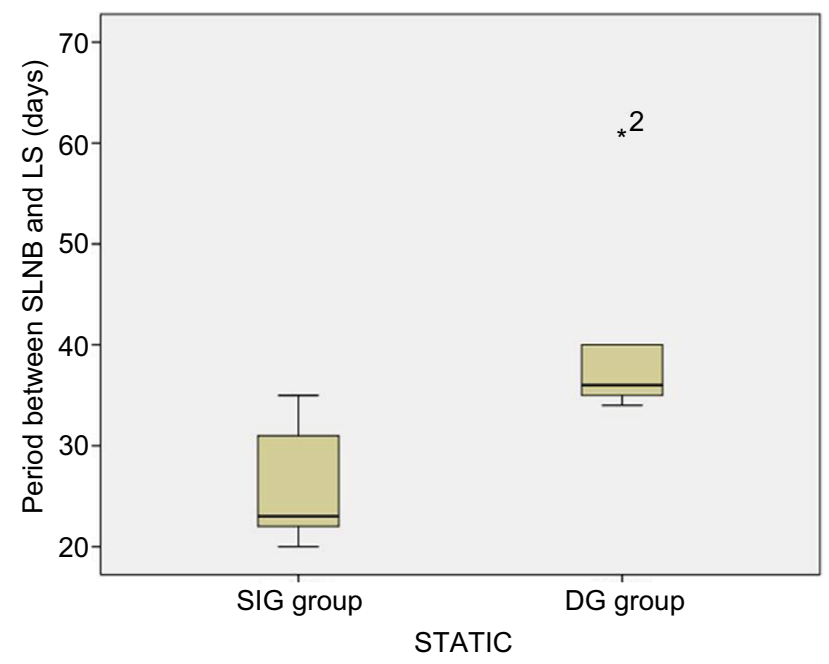

Figure 2 Box plot of the time elapsed between the SLNB and the post-SLNB scintigraphy scans regarding the subgroups sustained/increased versus decreased sites of afferent lymphatic inflow junctions, according to Static Image (STATIC).

Note: ${ }^{*} 2$ is an outlier case indexer.

Abbreviations: SLNB, sentinel lymph node biopsy; SIG, sustained/increased group; DG, decreased group; LS, lymphoscintigraphy.

lymphatic system is not an organ; instead, it connects different structures from small lymphatic capillaries to main ducts through lymph nodes and valves. Thus, each of those structures may be visualized in separate images from each other. The lymphatic system may also be involved in various diseases, including cancer and infectious diseases. ${ }^{33,56}$ This study chose to analyze lymphatic circulation by LS for recording physiological changes at different time periods following radiopharmaceutical injection to map lymph flow until reaching lymph nodes with immediate and delayed images. The visualizations of both the total number of evidenced lymph nodes and more axillary lymph nodes were also more representative in the most delayed images, corroborating the study by Sarri et al; ${ }^{49}$ the authors showed that the acquisition time determined the site of the afferent radiopharmaceutical inflow junction, identifying more lymph nodes in delayed images in patients with breast cancer submitted to surgery and axillary lymphatic approach. The inclusion of the quantitative analysis of the lymphatic flow rate using the angular coefficient (slope) aimed to identify small and still unnoticeable changes in the images and also to minimize errors of subjective interpretations in the qualitative analysis. Celebioglu et a ${ }^{57}$ used LS with qualitative and quantitative analyses to monitor patients submitted to SLNB. The second examination was performed 2-3 years after surgical treatment and radiation therapy, comparing the operated with non-operated arms, and no differences were detected between the limbs. We have found no other similar studies in the literature, with the exception of the study described above, conducted by Sarri et al. ${ }^{49}$ The three patients in our study who were submitted to immediate oncoplastic surgery exhibited an increased lymphatic flow rate in the early postoperative period. The compensation of lymphatic flow into the inflammatory area should be considered. ${ }^{58}$ The lymphatic system serves a key immunological function during the inflammatory process, promoting the influx of immune cells and specific antigens and draining into the lymph nodes with an increased drainage volume. ${ }^{59,60}$ We have found no studies for comparison that are similar to ours that assess the lymphatic circulation in the immediate pre- and postsurgical period of patients submitted to SLNB. Patients submitted to prophylactic mastectomy on whom SLNB was performed showed no significant increase in the risk of developing lymphedema.$^{61}$ Further studies using early and delayed postsurgery LS imaging should be conducted to identify the actual damage from SLNB to the lymphatic flow, especially when combined with more extensive breast surgery, including oncoplastic surgery.

This study showed no variation in the total number of lymph nodes identified pre- and post-SLNB. Probably, it can be explained by the small number of patients with a coincidental SLN draining the breast and upper limb, as described by Britton et $\mathrm{al},{ }^{40}$ and that will not have an impact on the development of late lymphedema. Perhaps, the association of many studies, including axillary reverse mapping too, can avoid injuring coincidental lymph vessels $\mathrm{s}^{41-44}$ and identify patients who may benefit from early physiotherapeutic stimulation ${ }^{49}$ after SLNB.

We have observed that the period between the SLNB and the LS was crucial to identify any variations in lymphatic flow, and that the period had an inverse relationship with flow: the longer the period between the SLNB and the monitoring of LS imaging is, the lower the lymphatic flow will be. These findings are exploratory. We studied only one patient following SLNB later. The lymphatic flow was evaluated at three different time periods by LS. The first scintigraphy was performed 15 days before the surgical procedure. The second examination was performed 22 days after surgery and the third one 6 months later. The immediate postoperative scintigraphy showed that the intensity of radiopharmaceutical uptake increased in the axillary lymph node, but the late postoperative study (6 months) showed a relatively lower uptake in this lymph node compared to the two previous studies. Maybe, these findings can be related to the acute inflammatory process after local manipulation and damage to the lymphatic chain in early postoperative evaluation and fibrosis in later evaluation. Further studies, focusing on different time periods between the SLNB and the LS combined with limb measurement, should be conducted to identify the actual impact of such a finding on conservative surgery. It would be important to assess which is the right timing to 
perform the lymphoscintigraphic study of the upper limb after conservative breast surgery and SLNB, in order to have the greater prognostic value in patients with an increased risk of lymphedema, such as obesity and radiotherapy.

\section{Conclusion}

Upper limb lymphatic flow gradually decreased after an SLNB in this study, but these results are exploratory because of the small sample size. Further studies are needed to confirm and to investigate more in depth these findings.

\section{Acknowledgment}

AJ Sarri is the father of VC Sarri. SM Moriguchi is the mother of PHM Cação, and they are both physicians in diagnostic imaging.

\section{Author contributions}

All authors contributed toward data analysis, drafting and critically revising the paper, gave final approval of the version to be published, and agree to be accountable for all aspects of the work.

\section{Disclosure}

The authors report no conflicts of interest in this work.

\section{References}

1. De Santis CE, Bray F, Ferlay J, Lortet-Tieulent J, Anderson BO, Jemal A. International variation in female breast cancer incidence and mortality rates. Cancer Epidemiol Biomarkers Prev. 2015;24(10):1495-1506.

2. Anton E, Botnariuc N, Ancuta E, Doroftei B, Ciobica A, Anton C. The importance of clinical and instrumental diagnostic in the mammary gland cancer. Rev Med Chir Soc Med Nat Iasi. 2015;119(2):410-418.

3. Kootstra JJ, Dijkstra PU, Rietman H, et al. A longitudinal study of shoulder and arm morbidity in breast cancer survivors 7 years after sentinel lymph node biopsy or axillary lymph node dissection. Breast Cancer Res Treat. 2013;139(1):125-134.

4. Aerts PD, De Vries J, Van der Steeg AF, Roukema JA. The relationship between morbidity after axillary surgery and long-term quality of life in breast cancer patients: the role of anxiety. Eur J Surg Oncol. 2011;37(4):344-349.

5. Cho Y, Do J, Jung S, Kwon O, Jeon JY. Effects of a physical therapy program combined with manual lymphatic drainage on shoulder function, quality of life, lymphedema incidence, and pain in breast cancer patients with axillary web syndrome following axillary dissection. Support Care Cancer. 2016;24(5):2047-2057.

6. Lopez Penha TR, van Roozendaal LM, Smidt ML, et al. The changing role of axillary treatment in breast cancer: who will remain at risk for developing arm morbidity in the future? Breast. 2015;24(5):543-547.

7. Shah C, Arthur DW, Wazer D, Khan A, Ridner S, Vicini F. The impact of early detection and intervention of breast cancer-related lymphedema: a systematic review. Cancer Med. 2016;5(6):1154-1162.

8. Ezzo J, Manheimer E, McNeely ML, et al. Manual lymphatic drainage for lymphedema following breast cancer treatment. Cochrane Database Syst Rev. 2015;(5):CD003475.

9. Lahtinen T, Seppälä J, Viren T, Johansson K. Experimental and analytical comparisons of tissue dielectric constant (TDC) and bioimpedance spectroscopy (BIS) in assessment of early arm lymphedema in breast cancer patients after axillary surgery and radiotherapy. Lymphat Res Biol. 2015;13(3):176-185.
10. Vieira RA, da Costa AM, de Souza JL, et al. Risk factors for arm lymphedema in a cohort of breast cancer patients followed up for 10 years. Breast Care (Basel). 2016;11(1):45-50.

11. Akita S, Mitsukawa N, Rikihisa N, et al. Early diagnosis and risk factors for lymphedema following lymph node dissection for gynecologic cancer. Plast Reconstr Surg. 2013;131(2):283-290.

12. Bulley C, Gaal S, Coutts F, et al. Comparison of breast cancer-related lymphedema (upper limb swelling) prevalence estimated using objective and subjective criteria and relationship with quality of life. Biomed Res Int. 2013;2013:807569.

13. Korpan MI, Chekman IS, Starostyshyn RV, Fialka-Mozer V. Національна наукова медична бібліотека України [Lymphedema: clinic-therapeutic aspect]. Lik Sprava. 2010;(3-4):11-20. Ukrainian [with English abstract].

14. Stuiver MM, ten Tusscher MR, Agasi-Idenburg CS, Lucas C, Aaronson NK, Bossuyt PM. Conservative interventions for preventing clinically detectable upper-limb lymphoedema in patients who are at risk of developing lymphoedema after breast cancer therapy. Cochrane Database Syst Rev. 2015;(2):CD009765.

15. Wenczl E. Daganatos betegekben kialakult másodlagos nyiroködéma ellátása [Management of secondary lymphedema in patients with cancer]. Orv Hetil. 2016;157(13):488-494. Hungarian [with English abstract].

16. Ridner SH, Dietrich MS, Kidd N. Breast cancer treatment-related lymphedema self-care: education, practices, symptoms, and quality of life. Support Care Cancer. 2011;19(5):631-637.

17. Krag DN, Weaver DL, Alex JC, Fairbank JT. Surgical resection and radiolocalization of the sentinel lymph node in breast cancer using a gamma probe. Surg Oncol. 1993;2(6):335-339; discussion 340.

18. Giuliano AE, Kirgan DM, Guenther JM, Morton DL. Lymphatic mapping and sentinel lymphadenectomy for breast cancer. Ann Surg. 1994;220(3):391-398; discussion 398-401.

19. Morrow M. Progress in the surgical management of breast cancer: present and future. Breast. 2015;24 Suppl 2:S2-S5.

20. Sagen A, Kaaresen R, Sandvik L, Thune I, Risberg MA. Upper limb physical function and adverse effects after breast cancer surgery: a prospective 2.5-year follow-up study and preoperative measures. Arch Phys Med Rehabil. 2014;95(5):875-881.

21. Rao R. The evolution of axillary staging in breast cancer. Mo Med. 2015; 112(5):385-388.

22. Rubio IT. Sentinel lymph node biopsy after neoadjuvant treatment in breast cancer: work in progress. Eur J Surg Oncol. 2016;42(3): 326-332.

23. Kuehn T, Bembenek A, Decker T, et al; Consensus Committee of the German Society of Senology. A concept for the clinical implementation of sentinel lymph node biopsy in patients with breast carcinoma with special regard to quality assurance. Cancer. 2005;103(3): 451-461.

24. Veronesi U, Paganelli G, Viale G, et al. Sentinel lymph node biopsy and axillary dissection in breast cancer: results in a large series. J Natl Cancer Inst. 1999;91(4):368-373.

25. Li CZ, Zhang P, Li RW, Wu CT, Zhang XP, Zhu HC. Axillary lymph node dissection versus sentinel lymph node biopsy alone for early breast cancer with sentinel node metastasis: a meta-analysis. Eur J Surg Oncol. 2015;41(8):958-966.

26. Soran A, Ozmen T, McGuire KP, et al. The importance of detection of subclinical lymphedema for the prevention of breast cancer-related clinical lymphedema after axillary lymph node dissection; a prospective observational study. Lymphat Res Biol. 2014;12(4):289-294.

27. Zurrida S, Veronesi U. Milestones in breast cancer treatment. Breast J. 2015;21(1):3-12.

28. Basso SM, Chiara GB, Lumachi F. Sentinel node biopsy in early breast cancer. Med Chem. 2016;12(3):273-279.

29. Bertozzi S, Londero AP. The sentinel lymph node biopsy for breast cancer over the years. Eur J Gynaecol Oncol. 2016;37(1):13-16.

30. Kim JY, Kim MK, Lee JE, et al. Sentinel lymph node biopsy alone after neoadjuvant chemotherapy in patients with initial cytology-proven axillary node metastasis. J Breast Cancer. 2015;18(1):22-28. 
31. Kibar S, Dalyan Aras M, Ünsal Delialioğlu S. The risk factors and prevalence of upper extremity impairments and an analysis of effects of lymphoedema and other impairments on the quality of life of breast cancer patients. Eur J Cancer Care (Engl). Epub 2016 Jan 13.

32. Ahmed M, Rubio IT, Kovacs T, Klimberg VS, Douek M. Systematic review of axillary reverse mapping in breast cancer. $\mathrm{Br} J \mathrm{Surg}$. 2016;103(3):170-178.

33. Szuba A, Shin WS, Strauss HW, Rockson S. The third circulation: radionuclide lymphoscintigraphy in the evaluation of lymphedema J Nucl Med. 2003;44(1):43-57.

34. DiSipio T, Rye S, Newman B, Hayes S. Incidence of unilateral arm lymphoedema after breast cancer: a systematic review and metaanalysis. Lancet Oncol. 2013;14(6):500-515.

35. Gebruers N, Verbelen H, De Vrieze T, Coeck D, Tjalma W. Incidence and time path of lymphedema in sentinel node negative breast cancer patients: a systematic review. Arch Phys Med Rehabil. 2015;96(6): 1131-1139.

36. Rebegea L, Firescu D, Dumitru M, Anghel R. The incidence and risk factors for occurrence of arm lymphedema after treatment of breast cancer. Chirurgia (Bucur). 2015;110(1):33-37.

37. De Gournay E, Guyomard A, Coutant C, et al. Impact of sentinel node biopsy on long-term quality of life in breast cancer patients. Br J Cancer. 2013;109(11):2783-2791.

38. Helyer LK, Varnic M, Le LW, Leong W, McCready D. Obesity is a risk factor for developing postoperative lymphedema in breast cancer patients. Breast J. 2010;16(1):48-54.

39. Mehrara BJ, Greene AK. Lymphedema and obesity: is there a link? Plast Reconstr Surg. 2014;134(1):154e-160e.

40. Britton TB, Solanki CK, Pinder SE, Mortimer PS, Peters AM, Purushotham AD. Lymphatic drainage pathways of the breast and the upper limb. Nucl Med Commun. 2009;30(6):427-430.

41. Boneti C, Korourian S, Bland $\mathrm{K}$, et al. Axillary reverse mapping: mapping and preserving arm lymphatics may be important in preventing lymphedema during sentinel lymph node biopsy. J Am Coll Surg. 2008;206(5):1038-1042; discussion 1042-1044.

42. Han JW, Seo YJ, Choi JE, Kang SH, Bae YK, Lee SJ. The efficacy of arm node preserving surgery using axillary reverse mapping for preventing lymphedema in patients with breast cancer. J Breast Cancer. 2012;15(1):91-97.

43. Noguchi M. Axillary reverse mapping for breast cancer. Breast Cancer Res Treat. 2010;119(3):529-535.

44. Thompson M, Korourian S, Henry-Tillman R, et al. Axillary reverse mapping (ARM): a new concept to identify and enhance lymphatic preservation. Ann Surg Oncol. 2007;14(6):1890-1895.

45. Bourgeois P, Leduc O, Leduc A. Imaging techniques in the management and prevention of posttherapeutic upper limb edemas. Cancer. 1998;83(12 Suppl American):2805-2813.

46. Baker JL, Pu M, Tokin CA, et al. Comparison of $[(99 \mathrm{~m}) \mathrm{Tc}]$ tilmanocept and filtered $[(99 \mathrm{~m}) \mathrm{Tc}]$ sulfur colloid for identification of SLNs in breast cancer patients. Ann Surg Oncol. 2015;22(1):40-45.
47. Clément O, Luciani A. Imaging the lymphatic system: possibilities and clinical applications. Eur Radiol. 2004;14(8):1498-1507.

48. Van Den Berg NS, Buckle T, Kleinjan GI, et al. Hybrid tracers for sentinel node biopsy. Q J Nucl Med Mol Imaging. 2014;58(2):193-206.

49. Sarri AJ, Moriguchi SM, Dias R, et al. Physiotherapeutic stimulation: early prevention of lymphedema following axillary lymph node dissection for breast cancer treatment. Exp Ther Med. 2010;1(1):147-152.

50. Schmidt-Hansen M, Bromham N, Hasler E, Reed MW. Axillary surgery in women with sentinel node-positive operable breast cancer: a systematic review with meta-analyses. Springerplus. 2016;5:85.

51. Bonneau C, Hequet D, Estevez JP, Pouget N, Rouzier R. Impact of axillary dissection in women with invasive breast cancer who do not fit the Z0011 ACOSOG trial because of three or more metastatic sentinel lymph nodes. Eur J Surg Oncol. 2015;41(8):998-1004.

52. Chen S, Liu Y, Huang L, Chen CM, Wu J, Shao ZM. Lymph node counts and ratio in axillary dissections following neoadjuvant chemotherapy for breast cancer: a better alternative to traditional pN staging. Ann Surg Oncol. 2014;21(1):42-50.

53. Petrelli F, Lonati V, Barni S. Axillary dissection compared to sentinel node biopsy for the treatment of pathologically node-negative breast cancer: a meta-analysis of four randomized trials with long-term follow up. Oncol Rev. 2012;6(2):e20.

54. McLaughlin SA, Bagaria S, Gibson T, et al. Trends in risk reduction practices for the prevention of lymphedema in the first 12 months after breast cancer surgery. J Am Coll Surg. 2013;216(3):380-389; quiz 511-513.

55. de Oliveira MM, Sarian LO, Gurgel MS, et al. Lymphatic function in the early postoperative period of breast cancer has no short-term clinical impact. Lymphat Res Biol. 2016;2016;14(4):220-225.

56. Bernaudin JF, Kambouchner M, Lacave R. La circulation lymphatique, structure des vaisseaux, développement, formation de la lymphe. Revue générale [Lymphatic vascular system, development and lymph formation. Review]. Rev Pneumol Clin. 2013;69(2):93-101. French [with English abstract].

57. Celebioglu F, Perbeck L, Frisell J, Gröndal E, Svensson L, Danielsson R. Lymph drainage studied by lymphoscintigraphy in the arms after sentinel node biopsy compared with axillary lymph node dissection following conservative breast cancer surgery. Acta Radiol. 2007;48(5): 488-495.

58. Lachance PA, Hazen A, Sevick-Muraca EM. Lymphatic vascular response to acute inflammation. PLoS One. 2013;8(9):e76078.

59. Aebischer D, Iolyeva M, Halin C. The inflammatory response of lymphatic endothelium. Angiogenesis. 2014;17(2):383-393.

60. Dieterich LC, Seidel CD, Detmar M. Lymphatic vessels: new targets for the treatment of inflammatory diseases. Angiogenesis. 2014;17(2): 359-371.

61. Miller CL, Specht MC, Skolny MN, et al. Sentinel lymph node biopsy at the time of mastectomy does not increase the risk of lymphedema: implications for prophylactic surgery. Breast Cancer Res Treat. 2012; 135(3):781-789.
Breast Cancer - Targets and Therapy

\section{Publish your work in this journal}

Breast Cancer - Targets and Therapy is an international, peerreviewed open access journal focusing on breast cancer research, identification of therapeutic targets and the optimal use of preventative and integrated treatment interventions to achieve improved outcomes, enhanced survival and quality of life for the cancer patient
Dovepress

The manuscript management system is completely online and includes a very quick and fair peer-review system, which is all easy to use. Visit http://www.dovepress.com/testimonials.php to read real quotes from published authors. 